University of Nebraska - Lincoln

DigitalCommons@University of Nebraska - Lincoln

\title{
Impacts of Land Use/Land Cover Change on Climate and Future Research Priorities
}

\author{
Rezaul Mahmood \\ Western Kentucky University, rmahmood2@unl.edu
}

Roger A. Pielke Sr.

University of Colorado at Boulder, pielkesr@cires.colorado.edu

Kenneth G. Hubbard

University of Nebraska-Lincoln, khubbard1@unl.edu

Dev Niyogi

Purdue University

Gordon Bonan

National Center for Atmospheric Research

Follow this and additional works at: https://digitalcommons.unl.edu/natrespapers

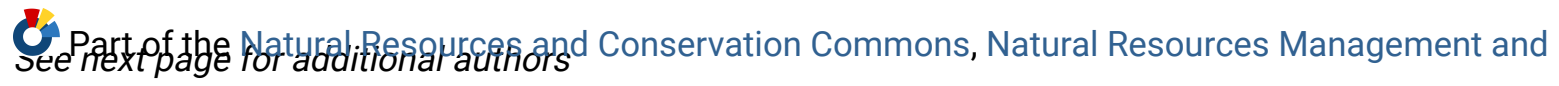
Policy Commons, and the Other Environmental Sciences Commons

Mahmood, Rezaul; Pielke, Roger A. Sr.; Hubbard, Kenneth G.; Niyogi, Dev; Bonan, Gordon; Lawrence, Peter; McNider, Richard; McAlpine, Clive; Etter, Andres; Gameda, Samuel; Qian, Budong; Carleton, Andrew; Beltran-Przekurat, Adriana; Chase, Thomas; Quintanar, Arturo I.; Adegoke, Jimmy O.; Vezhapparambu, Sajith; Connor, Glen; Asefi, Salvi; Sertel, Elif; Legates, David R.; Wu, Yuling; Hale, Robert; Frauenfeld, Oliver W.; Watts, Anthony; Shepherd, Marshall; Mitra, Chandana; Anantharaj, Valentine G.; Fall, Souleymane; Lund, Robert; Treviño, Anna; Blanken, Peter D.; Du, Jinyang; Chang, Hsin-I; Leeper, Ronnie; Nair, Udaysankar S.; Dobler, Scott; Deo, Ravinesh; and Syktus, Jozef, "Impacts of Land Use/Land Cover Change on Climate and Future Research Priorities" (2010). Papers in Natural Resources. 395.

https://digitalcommons.unl.edu/natrespapers/395

This Article is brought to you for free and open access by the Natural Resources, School of at DigitalCommons@University of Nebraska - Lincoln. It has been accepted for inclusion in Papers in Natural Resources by an authorized administrator of DigitalCommons@University of Nebraska - Lincoln. 


\section{Authors}

Rezaul Mahmood, Roger A. Pielke Sr., Kenneth G. Hubbard, Dev Niyogi, Gordon Bonan, Peter Lawrence, Richard McNider, Clive McAlpine, Andres Etter, Samuel Gameda, Budong Qian, Andrew Carleton, Adriana Beltran-Przekurat, Thomas Chase, Arturo I. Quintanar, Jimmy O. Adegoke, Sajith Vezhapparambu, Glen Connor, Salvi Asefi, Elif Sertel, David R. Legates, Yuling Wu, Robert Hale, Oliver W. Frauenfeld, Anthony Watts, Marshall Shepherd, Chandana Mitra, Valentine G. Anantharaj, Souleymane Fall, Robert Lund, Anna Treviño, Peter D. Blanken, Jinyang Du, Hsin-I Chang, Ronnie Leeper, Udaysankar S. Nair, Scott Dobler, Ravinesh Deo, and Jozef Syktus 


\section{IMPACTS OF LAND USE/LAND COVER CHANGE ON CLIMATE AND FUTURE RESEARCH PRIORITIES}

by Rezaul Mahmood, Roger A. Pielke Sr., Kenneth G. Hubbard, Dev Niyogi, Gordon Bonan, Peter Lawrence, Richard McNider, Clive McAlpine, Andres Etter, Samuel Gameda, Budong Qian, Andrew Carleton, Adriana Beltran-Przekurat, Thomas Chase, Arturo I. Quintanar, Jimmy O. Adegoke, Sajith Vezhapparambu, Glen Conner, Salvi Asefi, Elif Sertel, David R. Legates, Yuling Wu, Robert Hale, Oliver W. Frauenfeld, Anthony Watts, Marshall Shepherd, Chandana Mitra, Valentine G. Anantharaj, Souleymane Fall, Robert lund, Anna Treviño, Peter Blanken, Jinyang Du, Hsin-I Chang, Ronnie Leeper, Udaysankar S. Nair, Scott Dobler, RaVINeSh Deo, and Jozef Syktus

$H$ uman activities have modified the environment for thousands of years. Significant population increase, migration, and accelerated socioeconomic activities have intensified these environmental changes over the last several centuries. The climate impacts of these changes have been found in local, regional, and global trends in modern atmospheric temperature records and other relevant climatic indicators.

An important human influence on atmospheric temperature trends is extensive land use/land cover change (LULCC) and its climate forcing. Studies using both modeled and observed data have documented these impacts (e.g., Chase et al. 2000; Kalnay and Cai 2003; Cai and Kalnay 2004; Trenberth 2004; Vose et al. 2004; Feddema et al. 2005; Christy et al. 2006; Mahmood et al. 2006b; Ezber et al. 2007; Nuñez et al. 2008). Thus, it is essential that we detect LULCCs accurately, at appropriate scales, and in a timely manner so as to better understand their impacts on climate and provide improved prediction of future climate.

The National Research Council (NRC 2005) has recommended the broadening of the climate change issue to include LULCC processes as an important climate forcing. The findings of this report state the following:

Regional variations in radiative forcing may have important regional and global climatic implications that are not resolved by the concept of global mean radiative forcing. Tropospheric aerosols and landscape changes have particularly heterogeneous forcings. To date, there have been only limited studies of regional radiative forcing and response. Indeed, it is not clear how best to diagnose a regional forcing and response in the observational record; regional forcings can lead to global climate responses, while global forcings can be associated with regional climate responses. Regional diabatic heating can also cause atmospheric teleconnections that influence regional climate thousands of kilometers away from the point of forcing. Improving societally relevant projections of regional climate impacts will require a better understanding of the magnitudes of regional forcings and the associated climate responses. 
In short, the above discussion clearly identified the importance of LULCC in the climate system.

It has also been established in the literature that biases, inaccuracies, and imprecision have been introduced to the climate monitoring systems because of meteorological station moves, instrument changes, improper exposure of instruments, and changes in observation practices (Davey and Pielke 2005; Mahmood et al. 2006a; Pielke et al. 2007a,b). Hence, we also need strategies that will help us to detect and overcome these biases and thus lead to an improved understanding of the role of land use forcing within the climate system.

The main objective of this essay is to propose a series of recommendations related both to detecting LULCC from observed climatic records and to modeling to improve our understanding of LULCC and its impacts on climate. We present these recommendations under two subgroups: 1) monitoring and data issues and 2) modeling.

MONITORING AND DATA ISSUES. It is important that there is a reliable surface observation platform. The recently commissioned U.S. Climate
Reference Network (USCRN) could be a good candidate for innovatively monitoring impacts of LULCC on near-surface atmospheric conditions, including temperature (Fig. 1). The USCRN measures temperature, precipitation, solar radiation, and ground or skin temperature. In addition, soil moisture, soil temperature, and relative humidity measurements will be added in the near future. The spatial distribution and suite of measurements should lead to better understanding of LULCC processes.

It has become clear from various studies (e.g., Pielke et al. 2007a) that data used in existing long-term climate assessments, including the U.S. Historical Climatology Network (USHCN), have undocumented biases that have not been corrected using data analysis and data adjustment techniques. As a result, it is proposed that data from a select subset of the USHCN stations or stations from similar networks within other countries with minimal bias could be used to determine impacts of LULCC on climate. It is also essential that we quantify all known biases and thus further continue to work on various data bias correction methods. In this process, we need to be mindful that changes in observation and data
AfFiliations: MaHmoOd, QUintANAR, ConNer, LeEPER, AND DOBLER-Department of Geography and Geology, and Kentucky Climate Center, Western Kentucky University, Bowling Green, Kentucky; Pielke and Beltran-Przekurat-Department of Atmospheric and Oceanic Sciences, Cooperative Institute for Research in Environmental Sciences, University of Colorado, Boulder, Colorado; HubBARD-High Plains Regional Climate Center, School of Natural Resource Sciences, University of Nebraska, Lincoln, Nebraska; NIYOGI-Departments of Agronomy and Earth and Atmospheric Science, Purdue University, West Lafayette, Indiana; BonAN-National Center for Atmospheric Research, Boulder, Colorado; LAWRenCE AND CHASE-Cooperative Institute for Research in Environmental Sciences, University of Colorado, Boulder, Colorado; MCNIDER AND Wu-Department of Atmospheric Science, University of Alabama, Huntsville, Alabama; McAlPINE AND DeO-Centre for Remote Sensing and Spatial Information Sciences, School of Geography, Planning, and Environmental Management, The University of Queensland, Brisbane, Australia; ETTER-Department of Ecologia y Territorio, Universidad Javeriana, Bogota, Colombia; GAMEDA AND QIAN-Agriculture and Agri-Food Canada, Ottawa, Ontario, Canada; CARLeton-Department of Geography, Pennsylvania State University, University Park, Pennsylvania; Adegoke and Vezhapparambu—Department of Geoscience, University of Missouri, Kansas City, Missouri; AsEFI AND NAIR-Department of Atmospheric Science, National Space Science and Technology Center, University of Alabama, Huntsville, Alabama; SERTEL-Department of Geodesy and Photogrammetry, Istanbul Technical University, Istanbul, Turkey; Legates-Center for Climatic Research, Department of
Geography, University of Delaware, Newark, Delaware; HALECooperative Institute for Research in the Atmosphere, Colorado State University, Fort Collins, Colorado; FraUenfeld-Cooperative Institute for Research in Environmental Sciences, National Snow and Ice Data Center, University of Colorado, Boulder, Colorado; WATTS - IntelliWeather, Chico, California; SHEPHERD AND Mitra-Department of Geography, University of Georgia, Athens, Georgia; AnANTHARAJ-GeoResources Institute, Mississippi State University, Mississippi State, Mississippi; Fall AND ChanGDepartment of Earth and Atmospheric Sciences, Purdue University, West Lafayette, Indiana; LUND-Department of Mathematical Sciences, Clemson University, Clemson, South Carolina; TreviñoDepartment of Geography and Anthropology, Louisiana State University, Baton Rouge, Louisiana; BLANKEN-Department of Geography, University of Colorado, Boulder, Colorado; DuUSDA ARS Hydrology and Remote Sensing Laboratory, Beltsville, Maryland; SYKTUS-Queensland Climate Change Centre of Excellence, Queensland Department of Environment and Resource Management, Indooroopilly, Brisbane, Australia

CORRESPONDING AUTHOR: Rezaul Mahmood, Department of Geography and Geology and Kentucky Climate Center, Western Kentucky University, 1906 College Heights Boulevard, Bowling Green, KY 42104

E-mail: rezaul.mahmood@wku.edu

The abstract for this article can be found in this issue, following the table of contents.

DOI:10.1175/2009BAMS2769.1

In final form 26 July 2009

(C) 2010 American Meteorological Society 
handling procedures could also introduce unexpected and or unnoticed biases in the data. It is important that we minimize such uncertainty in the data. Changepoint detection could be used for this purpose (Reeves et al. 2007). Moreover, since proximity of human settlements typically significantly affects the magnitude of LULCC and climate, the location of settlements need to be considered during establishment of new networks or analyzing data from already established networks. We also recommend that the National Climatic Data Center (NCDC) and other climate monitoring agencies develop plans and seek funds to address any monitoring biases that are identified and for which detailed analyses have not been completed.

Full advantage should be taken of the Climate Data Modernization Project (CDMP) to assess the impacts of LULCC. The CDMP, managed by the NCDC and in partnership with the Regional Climate Centers (RCCs), has photo documented the original climate observer forms from the nineteenth century held in the National Archives. These images are currently available online from the NCDC. The data from these photographs are currently being digitized and subjected to quality assurance. They will be available online after the work is completed. Sufficient priority must be assigned to the digitization and quality assurance efforts to ensure expeditious completion of this vital new dataset. The dataset must be supported by histories that describe the locations, instrumentation, observers, and the observational content of the climate stations whose records are being digitized. These histories are necessary as a source for identifying causes of perturbations in the digital record. Scores of such station histories were completed as part of the CDMP. Additional station histories must be developed for the remaining nineteenth-century stations that have extended periods of records. An attempt must be made to connect CDMP datasets with historical LULCC to better understand climate change.

Recently, there has been too much focus on meanstate variables, and expansion of the global-surface temperature dataset to include maximum and minimum temperatures is required. For example, minimum temperatures are sensitive to changes in climatic forcing (Walters et al. 2007; Pielke and Matsui 2005) and to land use or siting changes (Runnalls and Oke 2006). Global temperature datasets that include both maximum and minimum temperature should be expanded. Most current datasets used to detect greenhouse gas warming have focused on mean temperatures (e.g., Hansen et al. 1999). These mean tem-

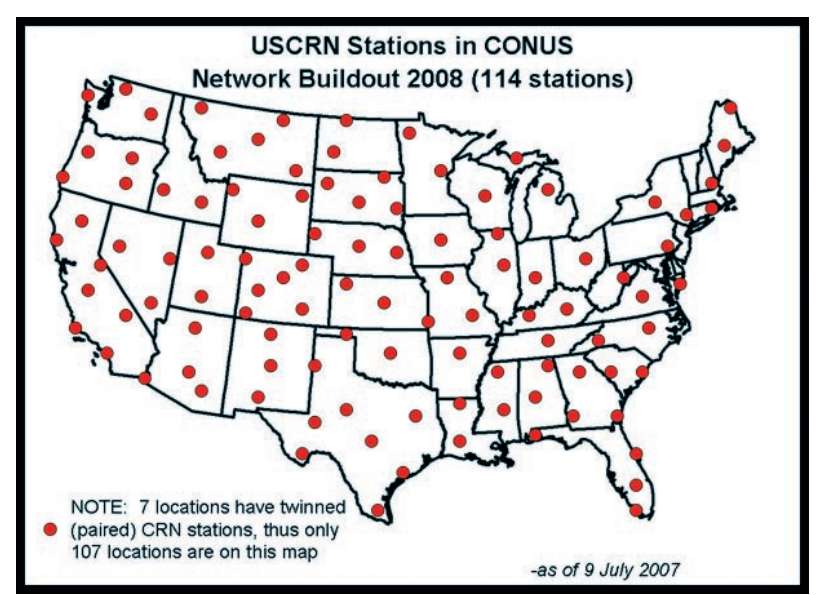

FIG. I. Location of USCRN stations.

peratures usually come from the average of maximum and minimum temperature observations. However, the partitioning into these two temperature metrics is not included in the most prominent datasets. The NCDC Global Historical Climatology Network (GHCN) dataset does separately track maximum and minimum temperature, but its coverage and the number of stations used make it questionable as a true global dataset. The NCDC should expand this dataset to include more stations by going back to the original records and parsing the minimum and maximum temperatures. We also agree with needs expressed by Parker et al. (2009) that ". . . for an improved global network monitoring all Global Climate Observing System (GCOS) Essential Climate Variables including humidity as well as temperature; for universal adherence to the GCOS Climate Monitoring Principles (www.wmo.ch/pages/prog/gcos/index.php? name = monitoringprinciples) which include the availability of full metadata such as photographic documentation; and as well for the rescue and digitization of all historical data."

The maximum and minimum temperature datasets are important because minimum temperature alone is almost certainly not a good parameter to detect heat accumulation in the atmosphere associated with added anthropogenic greenhouse gases or other climate changes (Pielke and Matsui 2005). In addition, minimum temperature is much more sensitive to land use change than maximum temperature (Hale et al. 2008; Runnals and Oke 2006). Most importantly, the nighttime boundary layer is very shallow and is decoupled from the deeper atmosphere. The stable nocturnal boundary layer does not measure the heat content in a large part of the atmosphere where the greenhouse signal should be the largest (Lin et al. 2007; Pielke et al. 2007a). 
Because of nonlinearities in some parameters of the stable boundary layer (McNider et al. 1995), minimum temperature is highly sensitive to slight changes in cloud cover, greenhouse gases, and other radiative forcings. However, this sensitivity is reflective of a change in the turbulent state of the atmosphere and a redistribution of heat rather than a change in the heat content of the atmosphere (Walters et al. 2007).

Additional challenges and uncertainties could be found associated with the wind effect on near-surface temperatures. If there is a trend in wind speeds, for example, there will be a diagnosed trend in temperatures measured at one level, even if there were no warming or cooling through the lower atmosphere. This is because wind alters the vertical distribution of heating and cooling near the ground, particularly with respect to nighttime temperatures. An increase in winds at night, for instance, is known to result in higher temperatures near the ground than otherwise would occur, as a result of greater vertical mixing. LULCC can alter the winds near the ground because of changes of the aerodynamic roughness, as well as from the effects of buildings and other obstacles to the airflow. Since the assessment of mean air temperature trends uses the minimum temperature in its construction, an increase in near-surface wind speed at night will introduce a warm bias.

While the impact of LULCC on the measurement of air temperature has been widely studied, its impact on precipitation measurement may be even more dramatic and uncertain. Much work has focused on the effects of urbanized areas on clouds, rainfall patterns, and lightning (e.g., Changnon et al. 1971; Huff and Schickedanz 1974; METROMEX 1976; Jauregui and Romales 1996; Shepherd et al. 2002; Shepherd 2006; Niyogi et al. 2006; Mote et al. 2007; Stallins and Rose 2008; Hand and Shepherd 2009; Kishtawal et al. 2009), usually with a conclusion that precipitation or lightning is increased downwind owing to the enhanced convection associated with the urban-related heat island, surface roughness, or pollution.

It is widely known that precipitation data are adversely affected by a nontrivial precipitation gauge undercatch bias-monthly estimates of this bias often vary from $5 \%$ to $40 \%$ for the continental United States (Legates and DeLiberty 1993a,b; Groisman and Legates 1994, 1995). This bias is largely due to the deleterious effect of the wind on snowfall; although the effect of wind on rainfall is smaller, it is nevertheless significant ( 5\%; Legates and DeLiberty 1993b). Globally averaged, the undercatch bias is about $11 \%$ (Legates 1987). Splashing effects, mechanical errors (e.g., friction of pen plotters and tipping bucket problems associated with heavy rainfall and clogged funnels), and human errors (e.g., improper recording of the timing and/or amount of precipitation) also contribute to errors in precipitation gauge measurement. There is evidence that local LULCC can change the bias in precipitation gauge measurement, which can induce a spurious trend or mask an existing trend (Legates 1995).

Over time, many precipitation measurement sites have become more urbanized and experienced growth of trees in the vicinity. Such changes are slow and gradual but serve to decrease the wind field across the gauge orifice. This can lead to a spurious increase in the measured precipitation even if the actual precipitation remains unchanged because the gauge measurement bias decreases with decreasing wind speed. Similarly, urbanization results in a slight warming of the local air temperatures due to the urban heat island effect. In regions and seasons where the mean monthly air temperature is at or slightly below freezing (Legates and Bogart 2009), a slight change in air temperature can alter the proportion of the precipitation that falls in solid (e.g., snow and ice) form; since the bias is much greater for snowfall than rainfall (liquid form) events, the measured precipitation will also exhibit a spurious increase. Legates (1995) demonstrated that a spurious increase in precipitation of $13 \%$ could be induced by a simple $1{ }^{\circ} \mathrm{C}$ increase in air temperature and a $0.5 \mathrm{~m} \mathrm{~s}^{-1}$ decrease in wind speed. Thus, LULCCs that affect the wind speed across the gauge orifice and the proportion of precipitation that falls as snow can induce spurious trends in time series of precipitation.

Two issues have become evident from the above discussion on precipitation: 1) LULCC can provide a false sense of change in actual type and amount in the vicinity, and 2) LULCC effects can be detected from these changes. Therefore, it is important that future research separates the impacts of LULCC on precipitation type and amount and actual bias. More research should be undertaken to separate these components using existing datasets. Additionally, as noted above, the USCRN could also provide more accurate data in the future to detect the impacts of LULCC on precipitation.

Surface fluxes of latent and sensible heat and $\mathrm{CO}_{2}$ and their changes over time could also be good indicators of the impacts of the LULCCs on surface boundary conditions. Thus, the scientific community should continue to monitor surface fluxes using existing networks (e.g., AmeriFlux) and add new and similar observational platforms. This would increase the spatial density of observation points and representation of the 
various LULC types, thereby allowing more effective monitoring and recording of smaller-scale changes and their impacts on climate. In the monitoring of fluxes, an easily accessible and well-maintained central data repository needs to be established. Examples of the most prominent and easily noticeable LULCCs and their impacts could be found in urbanization and expansion of agricultural land use. As a result, we strongly call for the design and implementation of such campaigns in the near future.

In addition to the use of data from in situ measurements, remotely sensed data could play an important role in detecting and monitoring LULCC. For example, the Normalized Difference Vegetation Index (NDVI) and similar indices derived from optical remote sensing data have been widely used in LULCC detection. However, more accurate satellite data with higher resolution and continuity are needed for appropriate representation of local and regional LULCC. The availability of complementary datasets is also important for successfully utilizing satellite data. In addition, regular acquisition of such data is affected by atmospheric composition with respect to water vapor and aerosols, clouds, and shadows. A major limitation of the passive optical remote sensing data is that they can only "see" a very thin layer of the Earth's surface and are unable to provide important information such as vegetation woody biomass, soil moisture, and snow depth. These limitations can be effectively compensated by microwave and light detection and ranging (lidar) observations with their high sensitivity to feature dielectric properties, deeper penetration depth, and all-day, all-weather operational ability.

Theoretical radiative transfer modeling (Chen et al. 2003; Du et al. 2006) and its applications in global and regional studies (Jackson et al. 1999) have proved the effectiveness of using active and passive microwave sensors to monitor large-scale vegetation conditions, soil moisture, and snow properties. Decades-long observations from multiple microwave sensors, such as the Scanning Multichannel Microwave Radiometer (SMMR), Special Sensor Microwave Imager (SSM/I), Advanced Microwave Scanning Radiometer for Earth Observing System (AMSR-E), WindSAT, and the European Remote Sensing Satellite (ERS) wind scatterometer have provided unique datasets for LULCC studies. In addition to direct detection of LULCC using microwave remote sensing observations, it is also an urgent task to fully integrate these data with microwave-retrieved information into climate-land surface models by techniques such as data assimilation.
Some newly developed remote sensing techniques provide a better description of vegetation vertical structure, such as Polarimetric Interferometric Synthetic Aperture Radar (PolInSAR), multi-angle optical remote sensing, and lidar. The Geoscience Laser Altimeter System (GLAS) provides an unprecedented dataset of vegetation heights. These data have been used successfully to estimate vegetation heights in various forest regions (Harding and Carabajal 2005; Lefsky et al. 2005, 2007). As described in NRC (2007), several spaceborne lidar sensors-such as the Ice, Cloud, and Land Elevation Satellite II (ICESat II); the Deformation, Ecosystem Structure and Dynamics of Ice (DESDYNI); and Lidar Surface Topography (LIST) - will be launched in the near future. From these sensors, vegetation vertical height and structure parameters would be estimated and their changes could be determined.

MODELING. The authors recognize that there are a significant number of models currently available that include a representation of LULCC and their impacts on climate. Nonetheless, the scientific community needs to continue to reevaluate how well these models represent the true complexity of the land surface. Moreover, it is necessary to examine whether vegetation models are sufficiently advanced to represent complex biochemical reactions and feedbacks associated with spatial and temporal changes (e.g., phenology). Current land surface and atmospheric models are suitable for assessing some impacts of land cover change (e.g., prescribed vegetation cover). However, uncertainties exist in representing vegetation dynamics (e.g., gradual transition) and this issue needs to be addressed. It is important to recognize that land use change (e.g., where intensity of land use is a variable) or mixed land use still remains a weak component in the models, and thus additional work is needed.

As an example of the deficiencies in the current models that have been used in climate assessments, Lawrence and Chase (2007) showed that replacing the standard land surface parameters in the National Center for Atmospheric Research (NCAR) Community Climate System Model 3.0 (CCSM 3.0) with parameters consistent with Moderate Resolution Imaging Spectroradiometer (MODIS) satellite observations resulted in a $10 \%$ increase of both bare soil fraction and leaf area index (LAI). These increases also led to large improvements in surface albedo with consequent improvements in simulation of precipitation and near-surface air temperature. However, the increased LAI resulted in lower overall evapotrans- 
piration and reduced precipitation in the CCSM 3.0. This result suggests that while the new parameters significantly affected and improved the climate simulated in the Community Land Model 3.0 (CLM 3.0) and the CCSM 3.0, the new surface parameters have limited success in rectifying surface hydrology biases that result from the parameterizations within the CLM 3.0. This further emphasizes the complex role of the land surface in climate.

The assessment of the impacts of the spatial gradient of LULCC and vegetation dynamics (e.g., crop-forest dynamics; Carleton et al. 2008a,b) on the climate system needs to be pursued. An example is the alpine treeline, which has experienced rapid shifts in position in response to land use changes and climatic changes (e.g., Beniston et al. 1997; Gehrig-Fasel et al. 2007) with reported abrupt and dramatic meteorological changes over very small horizontal distances. For example, over a horizontal distance of less than $4 \mathrm{~km}$ separating alpine tundra from subalpine forest in the Rocky Mountains of North America, Blanken et al. (2009) measured lower air temperatures and relative humidity, higher wind speeds, converging daytime wind directions (downslope at tundra; upslope at forest), and lower net radiation in the alpine tundra compared to the subalpine forest. Thus, implications associated with these dynamics needs to be better understood because it is often at these boundaries that changes in land cover are occurring.

For modeling applications, classification of land use is important on finescales. However, models do not use land use classifications directly. Rather, they use fundamental physical parameters such as heat capacity (McNider et al. 2005), roughness lengths, and canopy resistance. Fundamental work is required to develop robust relationships between the land use class and these fundamental variables, such as has been applied in the studies of Steyaert and Knox (2008) and Strack et al. (2008). Additional focus on the statistical distribution of these parameters that characterizes LULCC is needed.

Water bodies, wetlands, and irrigation are also inaccurately represented in the models. Globally, numerous man-made lakes and/or reservoirs have been created over the last few decades (Marshall et al. $2003,2004)$. In addition, there are many examples of removing natural wetlands (e.g., Steyaert and Knox 2008). The impacts of these lakes and reservoirs and removal of wetlands on local and regional-scale climate systems are not well investigated; thus, LULCC studies should include assessments of these types of changes.
Comprehensive hydrological representation is critically needed to ensure realistic results of impacts of LULCC on the hydrologic cycle, including soil moisture. More effort is necessary to verify, monitor, and initialize the soil moisture component of models and how they interface with other model components. We must consider all of the direct and indirect feedback effects on hydrology related to LULC-induced changes.

FINAL REMARKS. As documented in this essay, we conclude that the finding of the National Research Council report (NRC 2005) that LULCC represents a first-order human climate forcing is a robust statement. LULCC effects must be assessed in detail as part of all future climate change assessments, including the forthcoming IPCC Fifth Assessment, in order for them to be scientifically complete. This includes not only climate effects in the regions where LULCC occurs, but also their role in altering hemispheric and global atmospheric and ocean circulations at large distances from the location of LULCC. We also conclude that a regional focus is much more appropriate in order to better understand the human effects on climate, including LULCC. It is the regional responses, not a global average, that produce drought, floods, and other societally important climate impacts.

The National Research Council report (NRC 2005) recommended that new climate metrics be developed to address this issue. They wrote

... the climatic effects from light-absorbing aerosols or land-use changes do not lend themselves to quantification using the traditional radiative forcing concept.... These challenges have raised the question of whether the radiative forcing concept has outlived its usefulness and, if so, what new climate change metrics should be used...

and 
1) The magnitude of the spatial redistribution of land surface latent and sensible heating (see, e.g., Chase et al. 2000; Pielke et al. 2002). The change in these fluxes into the atmosphere will result in the alteration of a wide variety of climate variables, including the locations of major weather features. For example, Takata et al. (2009) demonstrated the major effect of land use change during the period of $1700-1850$ on the Asian monsoon. As land cover change accelerated after 1850 and continues into the future, LULCC promises to continue to alter the surface pattern of sensible and latent heat input to the atmosphere.

2) The magnitude of the spatial redistribution of precipitation and moisture convergence (e.g., Pielke and Chase 2003). In response to LULCC, the boundaries of regions of wet and dry climates can change, thereby affecting the likelihood for floods and drought. This redistribution can occur not only from the alterations in the patterns of surface sensible and latent heat but also from changes in surface albedo and aerodynamic roughness (see, e.g., Pitman et al. 2004; Nair et al. 2007).

3) The normalized gradient of regional radiative heating changes. Because it is the horizontal gradient of layer-averaged temperatures that forces wind circulations, alterations in these temperatures from any human climate forcing will necessarily alter these circulations. In the evaluation of the human climate effect from aerosols, for example, Matsui and Pielke (2006) found that in terms of the gradient of atmospheric radiative heating, the role of human inputs was 60 times greater than the role of the human increase in the well-mixed greenhouse gases. Thus, this aerosol effect has a much more significant role on the climate than is inferred when using global average metrics. We anticipate a similar large effect from LULCC. Feddema et al. (2005), for example, have shown that global averages mask the impacts on regional temperature and precipitation changes.

The above climate metrics can be monitored using observed data within model calculations, such as those completed by Matsui and Pielke (2006) for aerosols, as well as by using reanalyses products, such as performed by Chase et al. (2000) with respect to the spatial pattern of lower-tropospheric heating and cooling. They should also be calculated as part of future IPCC and other climate assessment multidecadal climate model simulations.

The monitoring of existing climate metrics also needs to be significantly improved, as is discussed in our essay. With respect to surface air temperatures, for example, there needs to be an improved quantification of the biases and uncertainties in multidecadal temperature trends, which remain inadequately evaluated in assessment reports such as from the Climate Change Science Program (CCSP 2006). We also recommend that independent committees (perhaps sponsored by the National Science Foundation) conduct these assessments.

ACKNOWLEDGMENTS. The authors would like to thank the editor and the reviewers for their valuable comments and suggestions. These comments helped to significantly improve this manuscript. This paper is the outcome of a National Science Foundation-funded workshop entitled "Detecting the Atmospheric Response to the Changing Face of the Earth: A Focus on HumanCaused Regional Climate Forcings, Land-Cover/Land-Use Change, and Data Monitoring." It was held in Boulder, Colorado, on 27-29 August, 2007. The presentations can be found online at http://kyclim.wku.edu/Boulder.html and http://cires.colorado.edu/science/groups/pielke/links/ Detect/. The paper also benefited from USDA Grant 586445-6-068, the DOE ARM Program (08ER64674), NSF CAREER-0847472, and NASA's Terrestrial Hydrology Program. R. A. Pielke Sr., was supported on this study through the University of Colorado in Boulder (CIRES/ ATOC). The authors thank Dr. Bruce Baker for his valuable comments and suggestions during the workshop and for providing Figure 1. We would also like to thank Dallas Staley for her outstanding contribution in editing and finalizing the paper.

\section{REFERENCES}

Beniston, M., H. F. Diaz, and R. S. Bradley, 1997: Climatic change at high elevation sites: An overview. Climatic Change, 36, 233-251.

Blanken, P. D., M. W. Williams, S. P. Burns, R. K. Monson, J. Knowles, K. Chowanski, and T. Ackerman, 2009: A comparison of water and carbon dioxide exchange at a windy alpine tundra and subalpine forest site near Niwot Ridge, Colorado. Biogeochemistry, 95, 61-76, doi:10.1007/s10533-009-9325-9.

Cai, M., and E. Kalnay, 2004: Response to the comments by Vose et al. and Trenberth. Impact of land-use change on climate. Nature, 427, 214.

Carleton, A. M., D. L. Arnold, D. J. Travis, S. Curran, and J. O. Adegoke, 2008a: Synoptic circulation and land surface influences on convection in the Midwest U.S. "Corn Belt" during the summers of 1999 and 2000. Part I: Composite synoptic environments. J. Climate, 21, 3389-3414. 
- , D. J. Travis, J. O. Adegoke, D. L. Arnold, and S. Curran, 2008b: Synoptic circulation and land surface influences on convection in the Midwest U.S. "Corn Belt" during the summers of 1999 and 2000. Part II: Role of vegetation boundaries. J. Climate, 21, 3617-3641.

CCSP, 2006: Temperature Trends in the Lower Atmosphere: Steps for Understanding and Reconciling Differences. T. R. Karl, et al., Eds., Climate Change Science Program, 166 pp.

Changnon, S. A., F. A. Huff, and R. G. Semonin, 1971: METROMEX: An investigation of inadvertent weather modification. Bull. Amer. Meteor. Soc., 52, 958-967.

Chase, T. N., R. A. Pielke, T. G. F. Kittel, R. R. Nemani, and S. W. Running, 2000: Simulated impacts of historical land cover changes on global climate in northern winter. Climate Dyn., 16, 93-105.

Chen, K. S., T.-D. Wu, L. Tsang, Q. Li, J. Shi, and A. K. Fung, 2003: Emission of rough surfaces calculated by the integral equation method with comparison to three-dimensional moment method simulations. IEEE Trans. Geosci. Remote Sens., 41, 90-101.

Christy, J. R., W. B. Norris, K. Redmond, and K. P. Gallo, 2006: Methodology and results of calculating central California surface temperature trends: Evidence of human-induced climate change? J. Climate, 19, 548-563.

Davey, C. A., and R. A. Pielke Sr., 2005: Microclimate exposures of surface-based weather stations-Implications for the assessment of long-term temperature trends. Bull. Amer. Meteor. Soc., 86, 497-504.

Du, J., J. Shi, S. Tjuatja, and K. S. Chen, 2006: A combined method to model microwave scattering from a forest medium. IEEE Trans Geosci. Remote Sens., 44, 815-824

Ezber, Y., O. L. Sen, T. Kindap, and M. Karaca, 2007: Climatic effects of urbanization in Istanbul: A statistical and modeling analysis. Int. J. Climatol., 27, 667-679.

Feddema, J. J., K. W. Oleson, G. B. Bonan, L. O. Mearns, L. E. Buja, G. A. Meehl, and W. M. Washington, 2005: The importance of land-cover change in simulating future climates. Science, 310, 1674-1678.

Gehrig-Fasel, J., A. Guisan, and N. E. Zimmermann, 2007: Tree line shifts in the Swiss Alps: Climate change or land abandonment? J. Veg. Sci., 18, 571-582.

Groisman, P. Ya., and D. R. Legates, 1994: Accuracy of historical United States precipitation data. Bull. Amer. Meteor. Soc. 75, 215-227.

- , and — 1995: Documenting and detecting longterm precipitation trends: Where we are and what should be done. Climatic Change, 31, 601-622.
Hale, R.C., K. P. Gallo, and T. R. Loveland, 2008: Influences of specific land use/land cover conversions on climatological normals of near-surface temperature. J. Geophys. Res., 113, D14113, doi:10.1029/ 2007JD009548.

Hand, L., and J. M. Shepherd, 2009: An investigation of warm season spatial rainfall variability in Oklahoma City: Possible linkages to urbanization and prevailing wind. J. Appl. Meteor. Climatol., 48, 251-269.

Hansen, J., R. Ruedy, J. Glascoe, and M. Sato, 1999: GISS analysis of surface temperature change. J. Geophys. Res., 104, 30 997-31 022.

Harding, D. J., and C. C. Carabajal, 2005: ICESat waveform measurements of within-footprint topographic relief and vegetation vertical structure. Geophys. Res. Lett., 32, L21S10, doi:10.1029/2005GL023471.

Huff, F. A., and P. T. Schickedanz, 1974: METROMEX: Rainfall analyses. Bull. Amer. Meteor. Soc., 55, 90-92.

Jackson, T. J., D. M. Le Vine, A. Y. Hsu, A. Oldak, P. J. Starks, C. T. Swift, J. D. Isham, and M. Haken, 1999: Soil moisture mapping at regional scales using microwave radiometry: The Southern Great Plains Hydrology Experiment. IEEE Trans. Geosci. Remote Sens., 37, 2136-2151.

Jauregui, E., and E. Romales, 1996: Urban effects on convective precipitation in Mexico City. Atmos. Environ., 30, 3383-3389.

Kalnay, E., and M. Cai, 2003: Impact of urbanization and land use on climate change. Nature, 423, 528-531.

Kishtawal C., D. Niyogi, M. Tewari, R. A. Pielke Sr., and M. Shepherd, 2009: Urbanization signature in the observed heavy rainfall climatology over India. Int. J. Climatol., doi:10.1002/joc.2044.

Lawrence, P. J., and T. N. Chase, 2007: Representing new MODIS consistent land surface in the Community Land Model (CLM 3.0). J. Geophys. Res., 112, G01023, doi 10.1029/2006JG000168.

Lefsky, M. A., D. J. Harding, M. Keller, W. B. Cohen, C. C. Carabajal, F. Del Bom Espirito-Santo, M. O. Hunter, and R. de Oliveira Jr., 2005: Estimates of forest canopy height and aboveground biomass using ICESat. Geophys. Res. Lett., 32, L22S02, doi:10.1029/2005GL023971

—, M. Keller, Y. Pang, P. de Camargo, and M. O. Hunter, 2007: Revised method for forest canopy height estimation from the Geoscience Laser Altimeter System waveforms. J. Appl. Remote Sens., 1, 013537, doi:10.1117/1.2795724.

Legates, D. R., 1987: A Climatology of Global Precipitation. Publications in Climatology, Vol. 40, C. W. Thornthwaite, $84 \mathrm{pp}$. 
— 1995 : Precipitation measurement biases and climate change detection. Preprints, Sixth Symp. on Global Change Studies, Dallas, TX, Amer. Meteor. Soc., 168-173.

— in the United States Raingage Network. Proc. Symp. on Geographic Information Systems and Water Resources, Mobile, AL, American Water Resources Association, 547-557.

$\longrightarrow$, and — 1993b: Precipitation measurement biases in the United States. Water Resour. Bull., 29, 855-861.

— , and T. A. Bogart, 2009: Estimating the proportion of monthly precipitation that falls in solid form. $J$. Hydrometeor., 10, 1299-1306.

Lin, X., R. A. Pielke Sr., K. G. Hubbard, K. C. Crawford, M. A. Shafer, and T. Matsui, 2007: An examination of 1997-2007 surface layer temperature trends at two heights in Oklahoma. Geophys. Res. Lett., 34, L24705, doi:10.1029/2007GL031652.

Mahmood, R., S. A. Foster, and D. Logan, 2006a: The GeoProfile metadata, exposure of instruments, and measurement bias in climatic record revisited. Int. J. Climatol., 26, 1091-1124.

,-- , T. Keeling, K.G. Hubbard, C. Carlson, and R. Leeper, 2006b: Impacts of irrigation on 20thcentury temperatures in the Northern Great Plains. Global Planet. Change, 54, 1-18.

Marshall, C. H., Jr., R. A. Pielke Sr., and L. T. Steyaert, 2003: Crop freezes and land-use change in Florida. Nature, 426, 29-30.

$-, \ldots,-$, and D. A. Willard, 2004: The impact of anthropogenic land-cover change on the Florida peninsula sea breezes and warm season sensible weather. Mon. Wea. Rev., 132, 28-52.

Matsui, T., and R. A. Pielke Sr., 2006: Measurementbased estimation of the spatial gradient of aerosol radiative forcing. Geophys. Res. Lett., 33, L11813, doi:10.1029/2006GL025974.

McNider, R. T., A. J. Song, D. Casey, P. J. Wetzel, W. Crosson, and R. M. Rabin, 1995: Toward a dynamicthermodynamic assimilation of satellite surface temperature in numerical atmospheric models. Mon. Wea. Rev., 122, 2784-2803.

METROMEX, 1976: METROMEX update. Bull. Amer. Meteor. Soc., 57, 304-308.

Mote, T. L., M. C. Lacke, and J. M. Shepherd, 2007: Radar signatures of the urban effect on precipitation distribution: A case study for Atlanta, Georgia. Geophys. Res. Lett., 34, L20710, doi:10.1029/2007GL031903.

Nair, U. S., D. K. Ray, J. Wang, S. A Christopher, T. Lyons, R. M. Welch, and R. A. Pielke Sr., 2007: Observational estimates of radiative forcing due to land use change in southwest Australia. J. Geophys. Res., 112, D09117, doi:10.1029/2006JD007505.

Niyogi, D., T. Holt, S. Zhong, P. C. Pyle, and J. Basara, 2006: Urban and land surface effects on the 30 July 2003 mesoscale convective system event observed in the Southern Great Plains. J. Geophys. Res., 111, D19107, doi:10.1029/2005JD006746.

NRC, 2005: Radiative Forcing of Climate Change: Expanding the Concept and Addressing Uncertainties. National Research Council, 208 pp.

—, 2007: Earth Science and Applications from Space: National Imperatives for the Next Decade and Beyond. National Research Council, 456 pp.

Nuñez, M. N, H. H. Ciapessoni, A. Rolla, E. Kalnay, and M. Cai, 2008: Impact of land use and precipitation changes on surface temperature trends in Argentina. J. Geophys. Res., 113, D06111, doi:10.1029/2007JD008638.

Parker, D. E., P. Jones, T. C. Peterson, and J. Kennedy, 2009: Comment on "Unresolved issues with the assessment of multidecadal global land surface temperature trends by Roger A. Pielke Sr. et al." J. Geophys. Res., 114, D05104, doi:10.1029/2008JD010450.

Pielke, R. A., Sr., and T. N. Chase, 2003: A proposed new metric for quantifying the climatic effects of human-caused alterations to the global water cycle. Preprints, Symp. on Observing and Understanding the Variability of Water in Weather and Climate, Long Beach, CA, Amer. Meteor. Soc., CD-ROM, 3.4 .

- , and T. Matsui, 2005: Should light wind and windy nights have the same temperature trends at individual levels even if the boundary layer averaged heat content change is the same? Geophys. Res. Lett., 32, L21813, 10.1029/2005GL024407.

_-, G. Marland, R. A. Betts, T. N. Chase, J. L. Eastman, J. O. Niles, D. Niyogi, and S. Running, 2002: The influence of land-use change and landscape dynamics on the climate system-Relevance to climate change policy beyond the radiative effect of greenhouse gases. Philos. Trans., 360A, 1705-1719.

— C. Davey, and Coauthors, 2007a: Unresolved issues with the assessment of multi-decadal global land surface temperature trends. J. Geophys. Res., 112, D24S08, doi:10.1029/2006JD008229.

_ tainties and biases associated with surface temperature measurement sites for climate change assessment. Bull. Amer. Meteor. Soc., 88, 913-928.

Pitman, A. J., G. T. Narisma, R. Pielke, and N. J. Holbrook, 2004: The impact of land cover change on the climate of southwest Western Australia. J. Geophys. Res., 109, D18109, doi:10.1029/2003JD004347. 
Reeves, J., J. Chen, X. L. Wang, R. B. Lund, and Q. Lu, 2007: A review and comparison of changepoint detection techniques for climate data. J. Appl. Meteor. Climatol., 46, 900-915.

Runnalls, K. E., and T. R. Oke, 2006: A technique to detect microclimatic inhomogeneities in historical records of screen-level air temperature. J. Climate, 19, 959-978.

Shepherd, J. M., 2006: Evidence of urban-induced precipitation variability in arid climate regimes. J. Arid Environ., 67, 607-628.

- - H. Pierce, and A. J. Negri, 2002: Rainfall modification by major urban areas: Observations from spaceborne rain radar on the TRMM satellite. J. Appl. Meteor., 41, 689-701.

Stallins, J. A., and L. S. Rose, 2008: Urban lightning: Current research, methods, and the geographical perspective. Geogr. Compass., 2, 620-639, doi: 10.1111/j.1749-8198.2008.00110.x.

Steyaert, L. T., and R. G. Knox, 2008: Reconstructed historical land cover and biophysical parameters for studies of land-atmosphere interactions within the eastern United States. J. Geophys. Res., 113, D02101, doi:10.1029/2006JD008277.

Strack, J. E., R. A. Pielke Sr., L. T. Steyaert, and R. G. Knox, 2008: Sensitivity of summer near-surface temperatures and precipitation in the eastern United States to historical land cover changes since European settlement. Water Resources Res., 44, W11401, doi:10.1029/2007WR00654.

Takata, K., K. Saito, and T. Yasunari, 2009: Changes in the Asian monsoon climate during 1700-1850 induced by pre-industrial cultivation. Proc. Nat. Acad. Sci., 106, No. 24, doi:10.1073/pnas.0807346106.

Trenberth, K. E., 2004: Rural land-use change and climate. Nature, 427, 213.

Walters, J. T., R. T. McNider, X. Shi, W. B. Norris, and J. R. Christy, 2007: Positive surface temperature feedback in the stable nocturnal boundary layer. Geophys. Res. Lett., 34, L12709, doi:10.1029/2007GL029505.

Vose, R. S., T. R. Karl, D. R. Easterling, C. N. Williams, and M. J. Menne, 2004: Impact of land-use change on climate. Nature, 427, 213-214. 